\title{
CONSIDERAÇÕES ACERCA DA FILOSOFIA, DIREITO E ECOLOGIA
}

\author{
Vicente de Paulo \\ Barretto $^{1}$
}

Fábio Beltrami ${ }^{2}$

\begin{abstract}
Resumo
As relações entre homem e natureza sempre foram objeto de questionamento nos mais variados ramos, da religião à ciência. Como relacionar esses dois polos, desde a relação comportamental humana até os ramos do direito, num ponto convergente, é desafio para a reflexão humana. É com base nessa questão central que o presente artigo foi desenvolvido. As ferramentas para o enfrentamento desse desafio resultam da análise de três perspectivas de pensamento que diferentemente tratam da relação entre homem e natureza, quais sejam, o antropocentrismo, a ecologia e a responsabilidade solidária. Como se procura demonstrar, é nesta última que parece-nos repousar a melhor razão acerca da temática.
\end{abstract}

Palavras-chave: Antropocentrismo. Ecologia. Responsabilidade solidária. Direito. Natureza.

\section{INTRODUÇÃO}

As três áreas do conhecimento que titulam este texto constituem uma tríade temática que marcou o século XXI, antes mesmo do seu primeiro dia. Diferentes temáticas que, aparentemente, não se inter-relacionam entre si, mas de fato, como pretendemos demonstrar a seguir, são necessariamente complementares. Consideradas separadamente, surgem em diferentes momentos da história da humanidade. A primeira delas, a filosofia, constitui-se na cultura humana por volta do século VI a. C., como uma forma de pensamento, diferenciada das formas arcaicas para a explicação e o entendimento do cosmos e das relações sociais, próprias da cultura mitológica; a segunda, o Direito, concebido como fruto da vontade humana e não

\footnotetext{
${ }^{1}$ Livre-docente em Filosofia PUCRJ. Pós-doutor pela Maison des Sciences de L`Homme, Paris. Professor do Programa de Pós-Graduação em Direito da UNESA. Professor do Programa de Pós-Graduação em Direito da UNISINOS. Decano da Escola de Direito da UNISINOS. Professor visitante da Faculdade de Direito da Universidade de Coimbra. Consultor ad hoc da área de Direito e de Filosofia da CAPES. Consultor ad hoc da área de Direito do CNPQ. Membro do Board of Governors da International Association of Law Schools. Email: vpbarreto@terra.com.br
} 
mais como uma manifestação divina, resultou da aplicação dessa nova forma de pensar filosófica aos assuntos sociais e políticos no século V a.C.; e, por fim, a ecologia, em suas duas dimensões, a ecologia superficial e a ecologia profunda, que se desenvolve na segunda metade do século XX, com uma ontologia, uma epistemologia e uma axiologia especificas.

Para analisar a relação entre essas formas de conhecimento e como repercutiram na cultura humana, propomos seguir a ordem histórica com que se manifestaram. Iremos, inicialmente, situar a filosofia como expressão de um novo modo de pensar na cultura humana. Por volta de 600 a.c. ocorreu o que alguns historiadores denominaram como um ponto de inflexão na história da cultura grega. Em livro clássico sobre o assunto, Jean Pierre Vergnant (2002: p. 10-11) mostra como houve a passagem da cultura mitológica para cultura filosófica. Enquanto na época arcaica o conhecimento humano nascia da explicação mitológica, divina, dos fenômenos da natureza e das normas sociais, que da mesma forma expressavam a vontade dos deuses, a filosofia - essa nova forma de pensar - foi buscar na explicação dos fenômenos naturais na construção do logos, o discurso racional que procurava na própria natureza e no homem a explicação para os fenômenos e as leis. Nesse sentido é que podemos afirmar que os primeiros filósofos foram os filósofos da natureza, que se dedicaram a encontrar uma fonte original arkè para todos os fenômenos naturais. Os primeiros filósofos, Tales de Mileto à frente, não se ocupavam com o homem e o social, mas com a observação da natureza e foi, assim, como diria Aristóteles, que o homem diante do espanto face aos fenômenos naturais procurou identificar, através do logos, as causas e as leis primeiras do cosmos.

Esse transito entre duas formas de pensar e explicar o cosmos, e nele o homem e a cidade, realizou-se no contexto de uma sociedade que se organizou não mais em torno do palácio do monarca, a chamada cultura palaciana, mas da praça do mercado, a ágora. Na praça, surgiram as primeiras práticas de uma comunidade democrática, onde o direito tornava-se publicizado, norma geral que expressava a vontade da maioria dos cidadãos iguais e servia como marco regulatório das relações sociais.

O paradigma clássico da teoria do direito - autonomia individual, propriedade e responsabilidade - tem fornecido nos dois últimos milênios a estrutura teórica e prática da sociedade humana. Essa estrutura, entretanto, serviu como fundamento de um novo e revolucionário conjunto de normas, que reconhece o homem e a natureza como constituindo uma entidade integrada e que não podem ser considerados como entidades apartadas e, menos

\footnotetext{
${ }^{2}$ Doutorando em Direito Público Universidade do Vale do Rio dos Sinos. Professor no Centro de Ensino Superior Cenecista Farroupilha - CNEC Farroupilha. Professor na Faculdade da Serra Gaúcha - FSG. E-mail: fabio.beltrami@hotmail.com.br
} 
ainda, erigindo-se o homem como o proprietário da natureza. As intervenções do homem no espaço da natureza ou meio ambiental suscitaram novos desafios éticos, jurídicos e tecnológicos.

Foi esse paradigma jurídico, próprio da sociedade liberal- burguesa, e assentado num tripé , sendo a primeira perna, a propriedade como fato social gerador de relações particulares entre os cidadãos, a segunda perna desse tripé evidenciava-se no agente social central nas relações do homem com o seu entorno economico, a família; e, finalmente, como último pé do tripé da sociedade, do Estado e do Direito.

\section{AS RAÍzES DA ECOLOGIA PROFUNDA}

A ecologia profunda, talvez a mais contemporânea área da filosofia, procura dar consistência teórica a um conjunto de ideias e práticas, que reformulam radicalmente o conceito de natureza e de pessoa humana. Essa corrente de pensamento surgiu no quadro da constatação de como o modelo que consagrava o domínio do homem sobre a natureza mostrouse autodestrutivo e assim não garantiria a sobrevivência da própria espécie humana. O impasse em que se encontra a sociedade tecno-cientifica contemporânea remeteu à constatação de que os antigos talvez tenham tido razão ao afirmarem que a terra não pertence a homem, mas é o homem que pertence à terra.

Foram essas dificuldades em interpretar e explicar as relações do homem com a natureza que provocaram a elaboração do que se chamou de "ecologia profunda" ou " deep ecology", que tem também como sinônimos "ecologia radical", "biocentrismo", “ ecocentrismo" ou "igualitarismo ecológico". Sob todas essas denominações encontram-se abrigadas algumas questões nucleares adiantadas por filósofos e cientistas no correr do último século, mas que já tinham sido tangenciadas por diferentes autores em séculos passados. Trata-se de uma questão latente na cultura e que deita as suas raízes na Antiguidade quando a ideia de natureza veio associada a ideia representada pelo deus Pan, o deus mitológico metadehomem, metade-animal, protetor dos rebanhos e dos pastores, da vida selvagem. Pan, como escreve François Ost (2003: 150-151), nos leva para um universo pré-lógico, o mundo da fusão original, antes da separação das coisas e das ideias, dos gêneros e das espécies. Concebia-se um mundo integrado no seio da mãe natureza, a antiga Gaia genetrix, onde homem e natureza constituíam um todo. Essas são as ideias centrais que constituíram o que hoje chama-se de ecologia profunda e que interferem na teoria e na prática dos direitos ambientais. 


\section{NATUREZA COMO SUJEITO DE DIREITO? CASOS PARADIGMÁTICOS}

Esse processo que levou a uma revisão das relações do homem com a natureza, eixo temático e axiológico da ecologia profunda e DNA do direito ambiental, passou por diversas mutações. Mutaç̃os essas que se referiam aos homens, aos animais, à terra, aos seres que aqui habitam e que, por óbvio, se mostram distintos em características essenciais e acidentais. A questão não se resume na diferença ontológica entre ambos, ou então no questionamento acerca da possibilidade de identificação de sujeitos jurídicos e éticos para os "a(qu)lémhomens", ou ainda, como algo que se constitúa em evidência para determinado momento da historia humana e hoje se mostra como um abismo quase insuperável? A visão tradicional impunha-se no paradigma que perdurou na cultura do Ocidente até o século XVI: a natureza existia unicamente para servir aos interesses humanos. (THOMAS, 2010: 21)

Não raro são os exemplos onde tais questionamentos se mostraram ao judiciário atual e de época, não meramente como "objeto" de um desígnio estatal ou privado que mereça ser solucionado, mas como a possibilidade real de se pensar e designar certas espécies naturais, que tinham características distintas daquelas encontradas no homem. Tratava-se de considerar novos sujeitos de direito, contrariando desta forma a visão antropocentrista do mundo. Vejamos, em alguns exemplos históricos, relatados por Luc Ferry (2009) e François Ost (1995), como se manifestava esse entendimento do homem considerado senhor absoluto da natureza e o choque dessa concepção com as correntes ecológicas.

No ano de 1587, os habitantes do vilarejo de Saint-Julien, incomodados com a presença de uma colônia de gorgulhos da classe dos insetos, ajuizaram junto ao juízo episcopal de SaintJean-de-Maurienne, sob a alegação de que ditos insetos prejudicavam os vinhedos, causando estragos consideráveis nas plantações. Os peticionários pediam então ao vigário-geral do bispado de Mauriene, que se dignasse a prescrever as medidas convenientes para aplacar a cólera divina e determinar, aplicando as leis, e mesmo por intermédio da excomunhão, ou qualquer outra censura apropriada, a expulsão dos insetos.

A situação apresentada, pareceria nos dias atuais bastante estranha, mas não foi na época, tanto que o procedimento junto ao juízo episcopal teve regular prosseguimento, com, inclusive, a nomeação de um advogado para defender os interesses dos insetos. Os argumentos da defesa dos insetos conseguiram desconstruir a sustentação dos advogados de acusação, o que suscitou na população um grande temor a ponto de convocação de uma assembleia 
comunitária para discutir o destino dos animais, que deveriam ser preservados com longe, é claro das vinhas. A decisão assegurava aos insetos, no entanto, um amplo espaço para alimentação e manutenção de suas vidas. Ofereceu-se então como habitat para os animais a praça da cidade e um lugar chamado Grand-Feisse, onde existiriam várias espécies de madeira, plantas e folhagens, que assegurariam alimentos para os insetos.

Como escreve Ferry (2009: 11), tratava-se de convencer os defensores dos insetos da boa vontade dos moradores da comunidade, ou seja, eles não queriam a eliminação dos insetos, bastava que os insetos não mais destruíssem as suas vinhas. Em outras áreas, poderiam viver tranquilamente. Poder-se-ia afirmar, então, que existiria um "contrato natural", um pacto com seres que tinham uma natureza diferenciada da encontrada entre os homens. No entanto, da sentença final não se tem notícia, possivelmente, a mesma se perdeu com o passar dos séculos ou foi comida pelos insetos, como escreve Ferry.

Processos como o mencionado não eram raros na Idade Média, tendo havido, por exemplo, outro caso ocorrido nas cercanias da cidade de Coire : a súbita irrupção de larvas de cabeça preta, corpo branco, da grossura do dedo mínimo e que caminhavam sobre seis pés, conhecida pelos lavradores pela expressão alemã de Laubkäufer. Ditas larvas entravam na terra no começo do inverno, atacando as raízes, secando as plantas ao final do verão e impossibilitando-as de desabrochar, o que causava enorme prejuízo. Indignados, os habitantes citaram os insetos destruidores diante do tribunal da província, constituindo advogado para os insetos e designando um promotor, observadas estritamente as formalidades da justiça. O juiz considerou que os insetos eram filhos de Deus e, portanto, tinham direito à vida e seria injusto privá-los de alimento e subsistência, e decidiu que a decisão mais justa seria relegar os mesmos numa região florestal e selvagem a fim de que não pudessem devastar as terras cultivadas.( Ferry, 2009:13)

A consideração de animais como "sujeito de direito" não significava que lhes eram atribuídos uma presunção de benefício. Todos os parâmetros jurídicos foram levados em consideração, inclusive a própria perda da natureza divina de tais animais, como ocorreu, em Berna, no ano de 1451. Neste ano sanguessugas invadiram um lago, e sem, obedecer a decisão do bispo local, que dera três dias para que se retirassem do lago, foram julgadas. O bispo teve o cuidado de recolher alguns exemplares de sanguessugas e apresentou-as fisicamente ao tribunal. Isto feito, em obediência ao devido processo legal foram amaldiçoadas, nas palavras do bispo: "Em nome de Deus todo poderoso, de toda a corte celeste, da santa Igreja divina, eu os amaldiçoo onde quer que estejam, e serão malditos, vocês e seus descendentes, até que tenham desaparecidos de todos os lugares". (Ferry, 2009: 14). Apesar do enquadramento como 
"seres de Deus" ou "pragas demoníacas" as sentenças pareciam levar em consideração algo que atualmente se perdeu, ou seja, os animais eram considerados como sendo mais do que um "objeto" a ser protegido, pois estabelecia-se com os seres humanos, sob a proteção divina, relações fundadas em direitos e deveres.

No entanto, é inegável que os processos como os mencionados acima causam estranheza, uma vez que não parece coerente considerar os animais, que não são seres dotados de liberdade, como sujeitos de direito no mesmo pé de igualdade com os homens. Poder-se-ia alegar que tais casos refletiam uma cultura própria do período histórico em que ocorreram, sendo que, atualmente, devido a apropriação da natureza, transformada em objeto passível de proteção e não sujeito de direito, mostra a dificuldade que temos em compreender esses procedimentos. De fato, é inegável que o momento histórico era outro, no entanto, apesar da apropriação da natureza na atualidade pelo homem como ser superior aos demais entes, ocorrem situações análogas, que suscitaram demandas judiciais.

Em 1972, a Suprema Corte Americana decidiu sobre o caso Sierra Club v. Morton ${ }^{3}$, 405 U.S. 727, arguido em 17 de novembro de 1971. A demanda versava sobre a preservação de um espaço ambiental que estava por sofrer modificações para dar lugar à construção de um parque público. Em 1970, o Forest Service dos EE.UU. concedera às empresas Walt Disney uma permissão, que a autorizava a "desenvolver" um vale selvagem no "Mineral King Valley", situado em Sierra Nevada, Califórnia. O orçamento de trinta e cinco milhões de dólares previa a construção de hotéis, restaurantes, brinquedos, enfim, um parque nos moldes da Disneylândia. A organização ecologista Sierra Club, entretanto, ajuízou uma ação para impedir a construção do parque, alegando que o mesmo afetaria a estética e o equilíbrio natural do Mineral King Valley.

A ação proposta foi rejeitada em primeira instancia com a alegação de que a peticionante Sierra Club não demonstrara um interesse que justificasse a ação. $\mathrm{O}$ caso subiu então para ser julgado na segunda instância, e, antes da decisão, o professor de Direito da Faculdade de Direito da Universidade de Harvard, Christopher D. Stone, publicou um artigo intitulado "Should trees have standing? - Toward legal rights for natural objects" ${ }^{4}$, onde sustentou que, provavelmente, o prejuízo causado ao Sierra Club era pequeno, no entanto, o prejuízo sofrido pelo Mineral King, ou seja, o parque propriamente dito, não era. Tornava-se importante demonstrar, então, que o parque deveria ser considerado em si, como uma pessoa

\footnotetext{
${ }^{3}$ Disponível na página da US Supreme Court: https://supreme.justia.com/cases/federal/us/405/727/case.html. ${ }^{4}$ Disponível no banco de dados da Harvard em: http://isites.harvard.edu/fs/docs/icb.topic498371.files/Stone.Trees_Standing.pdf
} vol.09, nº. 03, Rio de Janeiro, 2016. pp. 
jurídica, no mesmo sentido de uma empresa. A decisão da Suprema Corte norte-americana mostrou-se um marco na história do direito ambiental: quatro juízes votaram contra o argumento de Stone de que a natureza tinha direitos, dois se abstiveram, mas três votaram a favor. Como escreve Ferry (2009: 21), pode-se dizer que as árvores perderam o processo por um voto.

Seguindo o argumento de Stones (1972: 07) o problema dos objetos da natureza é o mesmo problema dos declarados incapazes, que quando não mais possuem condições de resguardo dos próprios interesses, um defensor é nomeado como seu representante legal. $\mathrm{O}$ defensor não estará litigando em seu interesse próprio, mas no interesse do tutelado. $\mathrm{O}$ argumento foi construído levantando-se a semelhança com as pessoas jurídicas, que não têm vontade individual manifestada através da fala, própria dos seres autônomos e racionais como a pessoa humana.

A argumentação de Stones sustentava que, apesar das árvores, florestas ou qualquer outro objeto da natureza não possuírem a capacidade de falar, ou ainda, não possuírem "voz", isto, por si só, não é suficiente para demonstrar que as mesmas não possuem direitos. Stone argumenta que, da mesma forma, as empresas, os estados, os legalmente incompetentes também não possuem a capacidade de falar, e, por esta razão, torna-se necessário que alguém "fale" por eles, normalmente um advogado. Stone equipara o problema dos legalmente incompetentes com os problemas encontrados nas relações do homem com os demais seres da natureza. Sempre que alguém legalmente incompetente pretende arguir um direito perante uma corte, necessariamente terá um defensor na sua defesa. Ora, não seria o mesmo caso, pergunta Stone, com os demais seres da natureza? No caso mencionado, o Sierra Club não estava buscando a proteção de seus interesses, mas sim, se colocou como defensor dos interesses da natureza, do sujeito de direito "natureza". Desta forma, não cabia a decisão da corte que não aceitou o argumento do Sierra Club, em virtude de falta de interesse. O interesse que está em jogo, assim como o de um legalmente incompetente, não é o do seu defensor, mas, propriamente, no caso em análise, o da natureza.

Ao aproximar os objetos da natureza das corporações, das crianças, dos legalmente incompetentes, Stone demonstrou que tais objetos não são meramente coisas a serem protegidas em virtude da manutenção da existência humana, no sentido de que a afronta prejudicaria interesses inerentes ao ser humano, homo sapiens apenas; os objetos da natureza possuiriam também direitos inerentes a si próprios.

Resta examinar as condições propostas por Stone para que se possa atribuir direitos a um ser. Em primeiro lugar, é necessário que este ser possa ajuizar ações judiciais em seu vol.09, n. 03, Rio de Janeiro, 2016. pp. 
interesse; em segundo, o processo fornece os dados e argumentos para que juiz possa avaliar o dano ou o prejuízo causado a este ser, em si mesmo, e não, por exemplo, contra o seu proprietário; e, finalmente, que uma eventual reparação seja em benefício direto do sujeito de direito. E as árvores, e os demais seres naturais, conclui Stone, atendem a esses três requisitos e podem ajuizar ações por intermédio de seus representantes (associações de ecologistas, defensores públicos, ministério público, etc.).

Não podemos nos enganar com as aparentes inconsistências no argumento de Stone. Do ponto de vista pragmático, a argumentação de Stone tem certa coerência, pois permite, de facto, mover uma ação contra grandes poluidores, mesmo na ausência de um interesse explicito. Stone cita o caso de diversas empresas poluidoras do equilíbrio ecológico, que não podem ser impedidas de continuar agredindo a natureza em virtude do processo poluidor ocorrer em situações onde não se consegue determinar um interesse individual lesado.

Quais as conclusões que se extraem dos casos citados? Primeiro, é a clara diferença de tratamento dada aos objetos da natureza. Como sustentar que algo que no século XV e XVI era totalmente normal (conferir à natureza a característica de sujeito de direito) agora, no século XX passa a ser algo diverso, devendo ser objeto de debates jurídicos e de possibilidades de defesas acadêmicas para sustentar algo que outrora fora evidente? Conferir direitos à natureza, não como objeto de proteção, mas sujeito de direito gera uma estranheza que em séculos passados provocaria perplexidade. Não há como se furtar ao seguinte questionamento: Por quê?

O debate sobre os direitos da natureza na contemporaneidade procura decidir se o homem é o único sujeito de direito ou, ao contrário, se a "bioesfera", a "ecoesfera" ou "cosmos" têm os seus direitos. O homem seria, então, do ponto de vista ético e jurídico, um elemento entre muitos em um universo harmonioso e ordenado, mas que ele por sua ação provocava desequilíbrios pelos quais deveria ser responsabilizado.

\section{DA GAIA AO ANTROPOCENTRISMO}

Então Deus disse: "Faça-se o homem à nossa imagem e semelhança. Que este reine sobre os peixes do mar, sobre as aves do céu, sobre o gado e sobre a terra. "; "Frutificai-vos, disse, multiplicai-vos, povoai a terra e dominai-a. Reinai sobre os peixes do mar, sobre as aves do céu e sobre todos os animais que se arrastam sobre o solo. "; "Dou-vos toda a erva que semeia toda a superfície da terra, bem como todas as árvores de frutos com semente, este será o vosso alimento"; "Sejai fecundos, multiplicai-vos e povoai a Terra. Vós sereis objeto de temor 
e de assombro para todos os animais da terra, todas as aves do céu, tudo o que se arrasta sobre o solo e todos os peixes no mar: Eles são entregues nas vossas mãos. Tudo o que se move e vive vos servirá de alimento, dou-vos tudo isso como já vos dei a erva verde".

As passagens acima, constantes no Génesis, livro bíblico da criação, parecem atribuir um certo domínio da natureza aos homens, domínio este conferido por Deus. Evidente, que em várias outras passagens, a Bíblia demonstra a necessidade da moderação e a natureza divina da natureza, como vimos nos processos mencionados acima. No entanto, seria o domínio exercido pelos homens sobre os animais a característica de sujeito reinante sobre o mundo e sobre suas coisas? Essa pergunta é de fundamental importância. O movimento histórico evolutivo nos permite analisar fatores importantes - não necessariamente bíblicos - que demonstram a transição

Encontra-se em Descartes e noutros pensadores os indícios da ruptura entre homem e natureza. No entanto, tamanha ruptura, remonta à origem da espécie humana, pois desde então o homem intervém e transforma a natureza. O homem humaniza a terra, reveste-a de símbolos que a fazem falar uma linguagem para ele inteligível, o homem imprime a sua marca na terra, esta é a característica do homem moderno, a liberação das amarras cosmológicas e a sensação de dominação da natureza como um primado do homem, que o fazem procurar e adequar o ambiente natural a seus desejos, diferentemente do homem primitivo que não se arriscava a perturbar a ordem do mundo, não somente por medo de uma punição dita divina, mas por uma sensação de pertencimento àquele universo, onde natureza e sociedade, grupo e indivíduo, coisa e pessoa praticamente não se distinguem. (OST, 1995: 30).

Essa indistinção entre natureza e sociedade pode parecer estranha, na era do cogito, ego sum cartesiano. Nada mais esclarecedor do que a carta do índio cacique Seattle da tribo dos Sioux, em South Dakota, enviada ao então presidente dos Estados Unidos da América Francis Pierce, no ano de 1855, após o governo americano ter dado a entender que pretenderia comprar aquele território indígena. Essa carta evidencia o pensamento panteísta da harmonia natural e do papel do homem nesse ambiente, vejamos:

Para o meu povo, não há um pedaço de terra que não seja sagrado, uma agulha de pinheiro que cintila, uma margem arenosa, uma bruma leve no meio dos bosques sombrios. Tudo é sagrado aos olhos do meu povo. A seiva que cresce na árvore contém em si própria a memória dos peles-vermelhas. Cada clareira, cada inseto que zumbe é sagrado na memória e na consciência do meu povo. Nós fazemos parte da terra e ela faz parte de nós. Esta água cintilante que corre pelos riachos e rios não é apenas agua, é o sangue dos nossos ancestrais [...]. Porque, se tudo desaparecesse o homem poderia morrer numa grande solidão espiritual. Todas as coisas estão ligadas entre si. Ensinai às vossas crianças o que ensinámos às nossas sobre a terra: que ela é nossa mãe, e que tudo o que lhe acontece a nós e aos filhos da terra. Se o 
homem desdenha a terra, desdenha-se a si próprio. Disto temos a certeza. A terra não pertence ao homem, mas é o homem quem pertence à terra.

O homem primitivo via a ligação entre sua presença com algo superior, com a própria natureza em si, afinal, todas as coisas estão ligadas entre si, e ao desdenhar da terra o homem desdenha de si mesmo, pois, a terra não pertence ao homem, assim não pode ser loteada, comprada, ou vista com valores meramente monetários e exploratórios, ao contrário, o homem pertence à terra.

\section{Um mundo novo que se forma centrado no homem}

A relação entre homem e natureza passa, ao que parece, por constantes configurações histórico-evolutivas que permitem verificar claras diferenças no que se entende por "natureza", como sujeito de direito, ou como objeto, "coisa" a ser utilizada pelo homem a seu critério. Esse processo de "profanação" da natureza, que se inicia durante o século XVI, leva à separação entre o "homem primitivo" e o "homem moderno", a evolução do "bárbaro" para o "sujeito racional". A ideia do antropocentrismo ganha forma.

Conforme se extrai de Eckersley (1992: 51) o antropocentrismo é a crença na existência de uma linha divisória, clara e moralmente relevante entre a humanidade e o resto da natureza, sendo, que através deste viés, o ser humana torna-se a principal e única fonte de valor e significado para o mundo, relegando a natureza não-humana a um segundo plano, com função específica de servir ao homem nos seus interesses, já que estes se sobrepõem sobre quaisquer outros interesses distintos daqueles do homem. Tudo gira, então, ao redor do homem.

Neste contexto, a natureza se mostra meramente como uma ferramenta para o desenvolvimento do homem, uma fonte geradora de riqueza para o ser humano, que se torna, assim, como afirmava Protágoras no séc. IV a.C., como a medida de todas as coisas, das que são como são, das que não são como não são. No universo antropocentrista, a natureza é apenas o que circunda o ser humano, a periferia, não o centro, não podendo ser considerada sujeito de direito, uma entidade que não tem um valor absoluto em si mesma. (FERRY, 2009: $30)$.

Para François Ost (1995: 35), é durante o século XVII, que na Europa ocorreu a verdadeira viragem do movimento de apropriação da natureza pela espécie humana. A partir dessa época cunhou-se a ideia de que o ponto de vista do homem é o ponto de vista de domínio e de superioridade, ao se compreender não mais como centro do universo - em vista das descobertas de Copérnico - pois as amarras da natureza se quebram, o homem se libera da 
concepção de lugar fixo e imutável no Universo para a necessidade de compreensão e dominação desse movimento universal.

E aqui não se pode esquecer da importância de Sir Francis Bacon, e a concepção utópica formulada no livro Nova Atlântida (1617). Segundo Bacon, o Estado moderno deve ser concebido como uma república científica, onde o poder é exercido pela associação de sábios filantropos, que tem como um dos seus objetivos atingir o domínio completo da natureza com vistas a melhorar a condição do gênero humano. Essa utopia iria realizar-se, de acordo com Bacon, no continente que ele denominou de Nova Atlântida.

A história da Nova Atlântida se resume no seguinte: no final de uma longa viagem marítima, os viajantes atracam numa ilha desconhecida, convidados a conhecer a ilha, os viajantes se encontram então com os sábios da Casa de Salomão, que se dedicam ao estudo de toda a criação, procurando descobrir as causas e o conhecimento da natureza íntima das forças primordiais e dos princípios das coisas, para aumentar o império do homem sobre toda a natureza, ou seja, em última análise, o domínio do Universo pelo homem.

Como escreve Ost (1995: 37), Bacon busca as causas e o conhecimento da natureza íntima das forças primordiais o que permite, em primeiro momento, compreender, num segundo momento, imitar a natureza e, por fim, transformá-la, criando o autômato, a artificialidade. Esse ideal de ruptura com o "homem primitivo", encontra-se bem sintetizado na frase de Bacon: “A natureza”, escreve ele, “é uma mulher pública. Devemos domá-la, penetrar os seus segredos e subjuga-las à nossa vontade".

Foi essa instrumentalidade, essa profanação e "coisificação" da natureza que saltou aos olhos do cacique Seattle, personificação do suposto "homem primitivo" diante da racionalidade.

No entanto, não apenas Francis Bacon expressa tais ideais em meados do século XVII. Uma corrente de pensamento se formava que veio a ser conhecido como o Iluminismo. Para que o ser humano pudesse encontrar a verdadeira liberdade, o conhecimento e a felicidade, os Iluministas acreditavam que era necessário utilizar-se do pensamento racional para responder as suas dúvidas. Nesse diapasão, estimulava-se o questionamento, a investigação e a busca por explicações racionais dos fenômenos da natureza e da sociedade.

Os principais pensadores desse movimento foram René Descartes, Jean-Jacques Rousseau, François Marie Arouet Voltaire, John Locke, Montesquieu, François Quesnay e Adam Smith. Tal movimento ficou conhecido como o Iluminismo e a sua época como o "século das luzes", pois seus defensores acreditavam serem os propagadores da luz, fugindo da época das trevas. O Iluminismo acreditava, assim, no poder da razão, considerada como o vol.09, nº. 03, Rio de Janeiro, 2016. pp. 
instrumento investido de maior importância para a busca lógica do verdadeiro conhecimento e que tornava o homem qualitativamente diferente dos demais seres da natureza.

O ser Iluminista por defender a razão como o epicentro das coisas mudou a forma de pensar humana sobre os elementos naturais. Logo, a natureza que, na visão teocêntrica, era sagrada e tida como uma criação de Deus passou a ser vista como algo cuja existência poderia ser explicada através da ciência e do uso do pensamento racional. Nesse sentido, escreve Ferry (2009: 19), acerca do pensamento Iluminista sobre a natureza: “a natureza é (...) letra morta. No sentido próprio: ela não nos fala mais, pois deixamos há muito tempo - no mínimo desde Descartes- de lhe atribuir uma alma e acreditar habitada por forças ocultas".

Conforme escreve Ferry (2009: 19) o pensamento Iluminista modificou-se comparado ao pensamento teocêntrico. Nessa época, os animais eram vistos como sujeitos de direitos e submetidos a processos judiciais para que se comprovasse sua culpabilidade quando de uma invasão nos campos de plantio e, munidos de personalidade para que firmassem contrato com seres humanos, comprometendo-se a não mais invadirem suas terras, em troca de lugar em que pudessem viver bem, como fora mencionado nos exemplos aqui descritos.

Já no século das luzes, com relação aos outros seres que o cercavam, a visão era de que o homem, por ser provido de capacidade de racionalizar, estava no centro do universo e um grau acima de outros seres que não dispunham da mesma capacidade, pois só ele poderia ser visto como detentor da qualidade de pessoa moral e jurídica.

Não que os outros seres pudessem ficar dispostos à mercê das vontades humanas, pois, por mais que fossem desprovidos de razão e que não tivessem caráter de sujeitos de direitos, constituíam o ambiente habitado pelos sujeitos racionais, e a sua degradação poderia colocar em risco a própria existência dos homens e por isso mereciam ser respeitados e protegidos. Vale lembrar, que aqui o meio ambiente não tem um valor intrínseco, o fim visa o homem, ou seja, há a consciência de que ao destruir o meio que o cerca, o homem corra o risco de colocar sua própria existência em perigo, ou, no mínimo, não mais possuir as condições para uma vida dita boa sobre esta terra. (FERRY, 2009: 29-30)

Não obstante o pensamento iluminista, indiretamente a natureza merecia ser protegida não porque era elemento constitutivo do cosmos e sujeito munido de personalidade jurídica e de direitos, mas sim porque, ao passo que ela fosse degradada e se tornasse inexistente, a raça humana também estaria posta em risco.

Para Descartes, os animais - importantes elementos da natureza - deveriam ser conhecidos como animais-máquinas, pois reduzidos a meros seres não munidos de pensamento e incapazes de sentir qualquer tipo de emoção, não seria possível a sua equivalência aos seres vol.09, n. 03, Rio de Janeiro, 2016. pp. 
racionais.

Alguns pensadores iluministas chegaram a admitir que os animais não são máquinas, e que, além de não serem máquinas, são providos de emoções e capazes de sofrer. Dessa forma, portanto, os animais não são, ainda, sujeitos de direitos, mas por serem seres com sensibilidade, fazem florescer no ser iluminista um sentimento de compaixão, fazendo com que os animais mais próximos dos homens passem a serem protegidos por lei, de maus-tratos (FERRY, 2009: 114).

Para Kant, por exemplo, os animais não possuem direitos, mas são os homens que passam a ter deveres e respeitos a eles, podendo dispor da natureza, mas, respeitando-a e utilizando os seus recursos moderadamente. Em que consiste respeitar e usar os recursos naturais moderadamente? O pensamento kantiano permite que se responda essa pergunta de forma consistente, onde se estabeleçam critérios racionais que permita a delimitação do campo de uma ação humana moderada em relação à natureza. Isto porque, o kantismo que tem como núcleo central a ideia do ser humano como agente moral assegura um novo paradigma para as relações do homem com a natureza.

\section{UM RETORNO A GAIA, A PROPOSTA DA DEEP ECOLOGY}

Um retornar as origens, um retornar ao seio da mãe natureza, a Gaia Genetrix. Seria está uma possibilidade prática e teoricamente sustentável na época do homem sapiens e do dualismo cartesiano? Eis a questão que se propõe.

Correntes de pensamento contemporâneo sustentam ser de suma importância o desenvolvimento de uma consciência de interdependência de todos os seres vivos, bem como entre estes e a terra, onde vivem. Assim, como sustenta Ost (1995: 172) essa visão vê o mundo protegido por Pan, sendo o mundo de Pan o de um contínuo resvalar de deuses em homens e de homens em animais, um mundo sem fronteiras onde tudo está em tudo, um mundo de correspondências infinitas no seio da mãe natureza, a antiga Gaia genetrix. Ocorreria assim, novamente, uma sacralização da natureza, o qual promoveria uma reconciliação com as raízes mais antigas das nossas civilizações, num tempo em que o mundo ainda não estava desencantado. Esta ideia se parece muito com o trecho citado acima, do chefe da tribo, Seattle.

Essa proposta de retorno a mãe natureza tem sido significativamente trabalhada, inclusive, com propostas estabelecidas em teses jurídicas e éticas, o qual visam promover esta "reconciliação". Uma das correntes de pensamento que hoje em dia sustenta esses ideais leva o 
nome de "ecologia profunda" "deep ecology", por vezes referida como biocentrism, ecocentrism. Vejamos então seus principais pontos, seguindo entendimento de Ost (1995: 175)

A deep ecology tem a sua divindade (Gaia), os seus profetas (H.D. Thoreau, que apelava a uma oversoul, ou força moral de caráter divino que impregna toda a natureza, ou ainda A. Schweitzer, cujo famoso princípio Reverence for Life funciona como divisa do movimento), a sua bíblia (o Sand County Almanac, de Aldo Leopold, publicado em 1949, cujo capítulo Land Ethic exprime, pela primeira vez, a extensão da comunidade ética ao conjunto da biosfera), os seus povos eleitos (os native Americans, e, de maneira geral, todos os povos <primitivos> que souberam viver em osmose com a natureza), os seus locais nobres (os grandes parques nacionais americanos, como o Yellowstone e o Yosemite onde a wilderness foi arrancada a ferros da empresa da colonização humana), os seus grandes testemunhos (Heidegger, Marcuse, Ellul) e as suas palavras de ordem ( $<$ Pensar como uma montanha $>$, $<$ Earth first! $>$, $<$ Live and let live" $>$, $<$ Widening the circle $>$, $<$ Earth Wisdom>, <Declarations for interdependence>, <Liberation os life, of nature, of animals $>$...).

Verifica-se que a corrente de pensamento da ecologia profunda se mostra bem estruturada, e, resulta em consequências éticas e jurídicas, quando, por exemplo, como se extrai da passagem acima, tem como uma de suas palavras de ordem "widening the circle". Essa expressão, ainda que possa parecer simples no primeiro momento, tem todo um significado ético e jurídico, que traz um novo entendimento de "sujeito ético" e, principalmente, "sujeito de direito".

A ecologia profunda alarga o círculo para considerar não somente os homens como sujeito de direito, mas sim, ao alargar o círculo pretende fazer da natureza não mais um objeto de direito, moldável por disposições humanas, mas sim um sujeito de direito com dignidade própria a fazer valer direitos fundamentais que podem ser arguidos contra os seres humanos. Essa doutrina procura superar o antropocentrismo e o dualismo homem/natureza. A ecologia profunda, sustenta, então, que na contemporaneidade ocorre, necessariamente, a passagem do mundo antropocentrista para o universo biocentrico/ecocentrico.

Essa inversão de perspectiva ocasionará a perda do duplo privilégio que homem atualmente pensa possuir, o de ser a fonte exclusiva dos valores sociais. O homem não será mais a "medida de todas as coisas" e tal proposição receberá uma maior extensão conceitual, que será expressa na palavra de ordem da ecologia profunda "widening the circle". A revolução da deep ecology propõe a supressão de qualquer privilégio particular entre os seres da natureza, o homem agora passa a ser somente "um outro" no seio do alargamento do círculo. Passa o homem a adotar o ponto de vista da natureza (pensar como uma montanha), cuja perfeição de organização é fonte de toda racionalidade e todo o valor. (OST, 1995: 178).

Nessa perspectiva, então, o homem tem esvaziada a sua posição hegemônica de proprietário da natureza. Toda a ideia antropocentrica é contestada, todo o individualismo é vol.09, nº 03, Rio de Janeiro, 2016. pp. 
negado, verifica-se então, da citação acima, que a ecologia profunda, ao abrir o círculo, ao propor "pensar como uma montanha", necessariamente indica a passagem de um mundo individualista e dualista para o holista e a adoção de um rigoroso monismo, onde homem e natureza são um só ente.

Desta forma, pensando holisticamente, a integridade do todo e não somente do homem é que deve ser considerada, há que prevalecer o todo, sendo este a condição de possibilidade de todo o resto. Assim, entre direitos humanos e direitos da natureza, esses últimos devem prevalecer. Ao afastar o dualismo de homem versus natureza, toda distinção entre interno e externo resta abolida, toda hierarquia acaba dissolvida. (OST, 1995: 179).

Então, tem-se, por ora, algumas teses centrais da deep cology, quais sejam: Passagem de um mundo antropocentrista para um universo biocentrico; negação do dualismo homem versus natureza, substituída essa relação por uma concepção monística, ou seja, a indistinção entre o interno e o externo; a passagem de uma visão individualista para uma visão holística.

Parece-nos, que além de ser uma questão filosófica, com reflexos na ética e no direito, a ecologia profunda possui também uma esfera quase espiritual, no sentido de uma consciência, como uma espiritualidade. Um dos fundadores da deep ecology Arne Naess, inclusive, afirmou a necessária passagem de uma ecologia para uma ecosofia, em que componentes religiosos não estariam afastados.

Doze anos depois de ter estabelecido a diferença entre "ecologia simples" (shallow ecology) e "ecologia profunda" (deep ecology), Arne Naess, pai da ecologia profunda, propôs um catálogo de princípios básicos da ecologia profunda: o desenvolvimento da vida humana a não-humana na Terra representa um valor intrínseco, independentemente de sua utilidade para o homem. A diversidade da vida é um aspecto essencial e representa em si mesmo um valor. Os princípios subsequentes afirmam que o homem não tem o direito de reduzir a diversidade da vida, salvo para satisfazer as suas necessidades vitais. No entanto, a pressão exercida pelos homens sobre o mundo não humano é, atualmente, excessiva e exponencial, de modo que aqui uma das ideias mais controversas - seria necessária uma redução da população mundial a não mais de 100 milhões de habitantes (em perspectiva de 1982, quando Naess escreve). O sexto e sétimo princípios tratam de uma mudança radical da política e isto nos planos económico, tecnológico e ideológico, que procura o aumento constante dos níveis de vida, resultante desses diferentes objetivos (Ost, 1995:185). O oitavo princípio versa sobre a realização desses diferentes objetivos.

De fato, não se pode negar a radicalidade, em especial no que toca ao extermínio de parcela da população para que se tenha uma proteção plena, o que, parece-nos um contrassenso vol.09, n. 03, Rio de Janeiro, 2016. pp. 
e paradigma de difícil superação, vez que, exterminar enorme parcela para proteger outra se mostra exatamente o que a própria ecologia profunda combate.

Independente das críticas possíveis, tanto na perspectiva antropocêntrica como na da ecologia profunda, aqui somente se propõe descrever brevemente uma linha histórica, não operar nenhuma crítica. Busca-se uma reconstrução que conduza a um retorno aos exemplos citados dos animais como sujeitos de direito. O citado artigo de Stones é pedra angular para a renovação da discussão acerca dos primados jurídicos que elevariam "objetos" diversos do homo sapiens a condição de sujeitos de direito.

\section{ECOLOGIAS E ORDENAMENTO JURÍDICO}

Nesse quadro conceitual e doutrinário, onde se distinguem dois tipos de ecologia, Naess define resumidamente a ecologia superficial: "combate contra a poluição e o esvaziamento dos recursos tendo por objetivo central a saúde e a opulência das populações dos países desenvolvidos" (Naess, 1976:95). Essa tímida proposta de Naess suscitou críticas acerbas dos ecologistas radicais que mostravam como não tinha sido rompido com a perspectivas antropológica, pois a humanidade estaria protegida somente em virtude dos interesses da humanidade.

O vício que se encontra nessa perspectiva é que irá refletir-se em simples medidas legislativas e burocráticas, e que seria inocência esperar-se uma administração racional dos recursos naturais. Os ecologistas radicais sustentam que mudanças efetivas somente advirão de uma transformação espiritual pessoal, que será possível na medida em que se compreenda a sabedoria da terra, que inspirava os índios norte-americanos. Dessa sabedoria nasceria uma "consciência ecológica", consciente da integração do homem com o mundo.

Como então traduzir para a linguagem jurídica propostas ecológicas? A ecologia, escreve Ost, reivindica conceitos que englobam todas as manifestações da natureza e do processo evolutivo; o direito responde aos desafios da natureza através de critérios e categorias que pretendem regular a realidade. $O$ brado da chamada urgência ecológica aponta para a integração do processo de globalização com as demandas da natureza através do uso das categorias jurídicas e das leis.

Trata-se diante das variadas e múltiplas formas de regulação a que se propõe o direito (ordenação territorial, dispersão dos projetos de infraestrutura, impactos de intervenções no meio ambiente, etc.) verificar como são medidas inconsistentes e que atestam o fracasso da normatização relativa à proteção da natureza, da água, a regulação dos ruídos, a poluição 
atmosférica. Essas questões colocam o direito ambiental: a definição progressiva de princípios gerais, que possam dar certa coerência à matéria ou então estabelecer normas de caráter supranacional.

O direito no último século abriu-se para uma perspectiva global que supera a posição antropocêntrica e que se desenvolve em etapas:

1. Os primeiros textos internacionais, como a Convenção de Paris de 19 de março de 1902, protegiam somente os "animais" úteis para a agricultura e permitiu o sacrifício de espécies consideradas "nocivas";

2. Ocorreu um segundo momento quando a legislação passou a contemplar a proteção de espaços santuários naturais ou religiosos, como sendo parte da natureza a serem conservados com museus naturais. Em 1933, na Convenção sobre a África estabeleceu-se, pela primeira vez, a ideia da "espécie ameaçada de extinção".

3. A legislação do direito internacional passa a ocupar-se do meio- ambiente, na salvaguarda dos habitats ocupados pelas espécies ameaçadas.

4. Na Convenção do Rio de 1992, a proteção da natureza avançou coma tomada de consciência do valor intrínseco do patrimônio genético.

5. Pelas características do paradigma ecológico ocorre níveis de insegurança, cabendo ao direito transformar essa insegurança em segurança social.

6. Na esteira da judicialização da política, deparamo-nos com a ecologização do direito, adaptada à especificidade do meio a ser protegido, que são globais, complexos e dinâmicos por natureza. Essa judicialização da ecologia pressupõe:

a. Aplicação do direito considerando-se os valores que lhe são próprios: processo e lei anterior, publicidade das decisões, contraditório;

b. Torna-se necessário afastar todo o tipo de cientificismo, que consiste em atribuir ao perito-especialista uma ou outra forma de consciência e imparcialidade;

A judicialização da ecologia encontra-se ainda em estado embrionário, é incompleta e inconsistente e pode provocar efeitos perversos, tais como, instabilidade, hipertecnicidade, ineficácia da norma.

Vejamos então como nas duas instituições pilares do direito, a responsabilidade e o direito de propriedade situam-se diante dos desafios da ecologia. 


\section{Responsabilidade e futuro}

É na linha das possibilidades citadas no tópico anterior, que se apresenta uma teoria, defendida por doutrinadores que se diferenciam dos filósofos da deep ecology, mas que, não se furtam à discussão acerca de tal teoria, apesar de não haver total concordância com os preceitos da ecologia profunda. Encontram-se nesse caso François Ost, Paul Ricoeur e Hans Jonas.

Na Conferência das Nações Unidas do Rio de Janeiro, em 1992, uma questão colocada especialmente por países insulares fomentou, e fomenta até os dias atuais questões importantes, tais como: a possibilidade de um efeito estuda derivado de grande emissão de $\mathrm{CO}^{2}$ influenciar nas marés, prejudicando assim tais países insulares, bem como, e principalmente, se existiria uma meio de impor responsabilidades e soluções, quando se mostra evidente que o efeito estufa resulta da ação cumulativa de centenas de milhares de comportamentos individuais sem culpa ou dolo. (OST, 1995: 303).

Não parece que a saída jurídica se mostre como a única possível, pois esta se realiza unicamente através de discursos jurídicos de proteção, que podem, eventualmente, culminam em leis e sanções. O maior desafio da ética-filosófica no limiar do século XXI, principalmente tendo em os problemas suscitados pela genética e pela ecologia, consiste em repensar o próprio agir humano. Há a necessidade de se pensar uma nova construção ética (macro global) que fundamente a moral localista de cada sistema soberano, e, que essas novas formas de subjetividade humana possam refletir na esfera da política.

A frase de Ricoeur (1991: 281) situa as novas dimensões deste novo pensar ético, onde a responsabilidade ganha novos contornos: "A novos domínios correspondem novas responsabilidades". Essa nova teoria da responsabilidade diminui a carga subjetiva e o olhar para o passado e passa a considerar a ação humana em sua dimensão presente e futura.

É nesse sentido, que a citada frase de Ricoeur adquire plenamente o seu significado. A fundamentação da responsabilidade no horizonte do passado, no sentido de definir a responsabilidade como resultante da imputação causal por uma ação passada para então se analisar a possibilidade de sanção, não atende mais aos desafios que surgem na sociedade tecno-cientifica contemporânea. Como argumenta Ricoeur (1991: 281) há que se considerar o futuro, ou seja, no lugar de procurar os culpados por ações passadas, determinar e definir o círculo das pessoas solidariamente investidas de novas missões. Passa-se então, ao debate acerca do risco criado num horizonte futuro indeterminado, bem como, no envolvimento de categorias abstratas de pessoas como passíveis de responsabilização.

E, para comungar com a ideia de "defensores" que fala Stone, Jonas (2006: 54) 
sustenta que pela primeira vez na história da nossa civilização a magnitude e o campo de ação da práxis técnicas em seu conjunto e em todas as ações individuais e particulares são tais, que introduzem toda uma dimensão adicional e nova no marco do cálculo dos valores éticos, dimensão esta, que era desconhecida a todas as formas precedentes de ação humana. Por essa razão, torna-se necessário uma nova formulação racional dos preceitos éticos, que busque atender essa nova dimensão, e que vise, a partir de então, os homens como guardiões da natureza e das gerações futuras.

Diferente de alguns argumentos radicais da deep ecology, como, por exemplo, quando Naess propões a limitação da população global, a proposta de Jonas vai de encontro aos ideais ambientalistas que ainda mantém o homem no centro do universo, mas, que ,efetivamente, vestem com uma nova roupagem a natureza (como exemplo, a própria ideia de "guardião"), tanto é, que não seria viável, nem verdade, que possamos transferir nossa responsabilidade pela existência de uma humanidade futura para ela própria, dirigindo-nos simplesmente aos deveres para com aquela que irá existir, ou seja, cuidando do seu modo de ser. (JONAS, 2006: 93-94).

A isto se poderia pensar a ideia de "responsabilidade solidária", que fala Ost (1995: 310), ou seja, é possível defender uma concepção dialética da relação homem-natureza e que proteger a natureza é trabalhar, simultaneamente, para a restauração dos equilíbrios naturais e para a salvaguarda dos interesses humanos, vez que, os interesses humanos se assentam, precisamente e primeiramente em equilíbrios naturais. Tem-se na doutrina então, a ideia da responsabilidade solidária objetiva sobre os patrimônios comuns da humanidade.

Desta forma, Ost vai traçar os quatro elementos centrais da teoria, quais sejam: Responsabilidade; gerações futuras; patrimônio; e, humanidade. A Responsabilidade como responsabilidade-projeto torna-se assim mais do que mera imputação, estabelecida em relação causal com faltas do passado, pois tem por objetivo o futuro e destinatários as gerações futuras e não propriamente a natureza. Gerações futuras, no sentido de preservação a longo prazo das facilidades do consumo a curto prazo, algo além de duas gerações. Patrimônio, como ideia de uma conotação doméstica, de uma transmissão simbólica de bens que se passam de geração para geração, podendo ser entendido tal bem, como a própria terra e, Humanidade, associada à ideia do patrimônio, visando inscrever a transmissão numa linha virtualmente infinita, como um "quê" de "ainda possível", que caracteriza a perfectibilidade da sua natureza e lhe abre a via do projeto, como qualidade emergente das suas relações com os sujeitos e os objetos. (OST, 1995: 338-339).

\section{A concepção dialética de patrimônio}


Até então discutiu-se a problemática atinente à natureza e sua relação com o homem, sendo que, inúmeras questões restam pendentes, em especial aqui, a possibilidade de se pensar um estatuto jurídico pertinente ao paradigma ecológico, marcado por ideias holísticas, antes de tudo, e que confira forma jurídica, por exemplo, ao conceito econômico de "desenvolvimento sustentável", ou seja, os modos de produção que preservem a capacidade de regeneração dos recursos naturais, bem como, um regime jurídico que traduza a preocupação ética de assumir nossa responsabilidade perante as gerações futuras. Mas como fazer isto? (OST, 1995: 352).

Uma das análises que se faz necessária para a busca da possibilidade de se estatuir no ordenamento jurídico uma proteção ao ambiente, é acerca da categoria "patrimônio". Conforme o artigo 11, parágrafo primeiro do tratado internacional de 18 de dezembro de 1979 sobre a lua e demais corpos celestes, "a lua e seus recursos naturais constituem o patrimônio comum da humanidade". Pode soar estranho esse disposto, mas a ideia de tratar a lua como patrimônio comum da humanidade, possui bases jurídicas substanciais.

Ao considerar a lua e os demais corpos celestes como "patrimônio comum", toda a ideia acerca do conceito de "patrimônio" se mantém, tal qual a necessidade de proteção, conservação e administração além do conjunto de encargos inerente ao patrimônio. $\mathrm{O}$ patrimônio é um conceito transpessoal, que é, simultaneamente, de hoje, de ontem e de amanha, como uma herança do passado que, transitando pelo presente, se destina a dotar os hóspedes futuros do planeta. (OST, 1995: 354)

A leitura da categoria "propriedade", como diz Ost (1995: 354-355) deve ser aquela realizada de modo idêntico ao movimento da dialética, ou seja, com um olhar de dinamismo na categoria, fértil e dominante para a mesma, como exemplo: Da "minha” propriedade, passe-se ao patrimônio comum do grupo da nação, como no caso da lua; do simples ao complexo; de um regime jurídico ligado em direitos e obrigações individuais para um regime que prepondera os direitos difusos, ou seja, ao que parece o caminho da categoria "propriedade" poderá, no futuro, sofrer profundas alterações, superando a ideia de indivíduo pela de comunidade.

Essa natureza dialética de ver o patrimônio é de suma importância. François Ost (1995: 380-381) resume esta ideia em "cinco índices de complexidade", sendo o primeiro e o segundo a constatação de que o patrimônio implica uma dialética do sujeito e do objeto, do ser e do haver, ou seja, patrimonializar um espaço, um recurso, é reconhecer que nele são inscritos não apenas interesses de consumo, mas igualmente valores identificadores, uma via do porvir; já o terceiro índice resulta que a patrimonialização do bem seja inscrita numa lógica de solidariedade entre ativo e passivo, ou seja, se não há a capacidade de conserva-lo em estado 
original, ao menos deve-se garantir suas faculdades de regeneração; o quarto índice considera que tanto o interesse privado como o público devam coabitar no bem patrimonializado, vez que ai se verifica a presença do interesse de outrem; o quinto índice estabelece que o bem inscrito no registro do patrimônio comum ultrapassa o aqui e o agora, pois vem de mais longe e vai para mais longe, situa-se em uma outra escala que, abarcando o horizonte do presente e do local, os transcende simultaneamente.

Desta forma, é possível extrair que inobstante os objetos da natureza permanecerem como "coisas", ou seja, não há aqui os ideais plenos da deep ecology, podendo inclusive serem suscetíveis de apropriação, considera-se a proteção de um interesse superior, onde o regime jurídico busca seu fim, na ideia da proteção e da justiça, inclusive, com a transmutação e o alargamento dialético do conceito de patrimônio. Neste sentido é que a dimensão éticofilosófica assume a sua verdadeira dimensão ao servir como parâmetro de referência, como conhecimento auxiliar da regulação jurídica e da preservação da natureza.

\section{CONSIDERAÇÕES FINAIS}

A relação entre homem e natureza historicamente fora objeto de análise e de tentativas várias de associação e (co)relação, seja através de preceitos mitológicos, religiosos, filosóficos e científicos. O Direito, como umas das formas de regulação da vida em sociedade não se pode esquivar de tamanha conjunção, afinal, se faz necessário viabilizar, ainda que, sob um viés específico e passível de críticas, a relação institucional entre o homem e a natureza, seja através da designação desta última como objeto ou sujeito de direito.

A forma com que se vê a natureza à luz dos homens fora o que aqui se pretendeu elucidar. Várias correntes de pensamento histórica e filosoficamente relevantes se mostram divergentes, ocorrendo, atualmente, uma preponderância de um pensamento antropocentrista, que em outras épocas não assim o era, como nos mencionados processos canônicos em que animais apareciam como partes processuais enquadrados de modo superior à atual, de meros "objetos" a serem protegidos. Lembremos que a importância do debate transcende a ideia teocentrista (inobstante o livro Gênesis) de presunção de que todos os seres são "seres de Deus" e devem ser protegidos, tal qual sustentado nos processos canônicos, basta lembrar do artigo de Stone de 1972, que leva a questão da natureza da mesma forma de um legalmente incapaz, ou seja, embora não "fale" por si, mantém-se como sujeito de direito, conforme suas análises do caso Sierra Club v. Morton.

Se mostra clara a diferença de tratamento dada as "coisas" da natureza, no entanto, se 
mostra difícil de sustentar algo que em séculos passados se mostrava corriqueiro, atualmente se mostra diverso, ou seja, a atribuição de direitos à natureza, não como objeto de proteção, mas como sujeito de direito, sendo o homem um participe de um universo harmonioso e ordenado, o seio da mãe Gaia.

Subsídios históricos e filosóficos responsáveis pela modificação do pensamento não são difíceis de encontrar. Encontra-se em Descartes e noutros pensadores os indícios da ruptura entre homem e natureza, no entanto, não obstante o pensamento iluminista, indiretamente a natureza merecia ser protegida não porque era elemento constitutivo do cosmos e sujeito munido de personalidade jurídica e de direitos, mas sim porque, ao passo que ela fosse degradada e se tornasse inexistente, a raça humana também estaria posta em risco. Não nos parece haver aqui uma clara sensação de pertencimento ao universo, no sentido de Gaia, onde natureza e sociedade não se distinguem, parafraseando o chefe Seattle: Como posso vender a terra se ela não me pertence, e sim eu a ela.

Como visto, é na senda da ruptura com esse pensamento que aparece os teóricos da deep ecology, e sua visão ecocentrista/biocentrista. Tal visão implica diretamente em consequências éticas e jurídicas extraídas de sua máxima expressão "widening the circle". Alargar o círculo para considerar não somente os homens como sujeitos de direito, mas sim incluir a natureza, com dignidade própria a fazer valer. Supera o antropocentrismo e busca o ideal biocentrista, além da negação do dualismo homem versus natureza, substituída essa relação por uma concepção monística, e a passagem de uma visão individualista para uma visão holística.

Analisando profundamente os ideais da deep ecology, parece-nos que há um certo radicalismo nos seus preceitos, cite-se como exemplo, a proposta de Arne Naess de limitação da população global, o que nos parece um contrassenso e um paradigma de difícil praticidade, afinal, soa estranho (por mais que pareça antropocentrista) a defesa do extermínio de uma parcela de determinados seres para a manutenção da sobrevivência de outros. Há outras formas de se pensar uma solução.

Responsabilidade e futuro nos parecem ser uma forma adequada de se pensar esta solução, não que sejam exclusivas, mas se mostram mais coerentes do que os extremos mundotécnico e Gaia. É em autores como François Ost, Paul Ricoeur e Hans Jonas, que nos parece repousar a convergência entre os extremos mencionados.

A nova teoria da responsabilidade de Paul Ricouer passa a considerar a ação humana em sua dimensão presente e futura, ou seja, um olhar diverso do passado - tradição da ideia de responsabilidade atual resultante da imputação causal de uma ação passada - pois, dado os vol.09, n. 03, Rio de Janeiro, 2016. pp. 
desafios da sociedade tecno-científica atual, a ideia da responsabilização nos moldes atuais não mais se sustenta por si só. Há que se pensar num futuro indeterminado, o que, invariavelmente atinge toda uma dimensão ética, pois, ao envolver a possibilidade de um risco criado num horizonte futuro indeterminado, todo o conjunto de ações humanas e o cálculo dos valores éticos devem convergir para esta dimensão, novos imperativos éticos são necessários. Nesta senda de conclusão, os homens então passam a guardiões da natureza e das gerações futuras.

A isto se poderia pensar a ideia de "responsabilidade solidária", ou seja, é possível defender uma concepção dialética da relação homem-natureza sendo que proteger a natureza é trabalhar, simultaneamente, para a restauração dos equilíbrios naturais e para a salvaguarda dos interesses humanos, pois, os interesses humanos se assentam, precisamente e primeiramente em equilíbrios naturais. Tem-se na doutrina então, a ideia da responsabilidade solidária objetiva sobre os patrimônios comuns da humanidade. Essa os parece uma concepção coerente acerca da relação homem-natureza, e aqui se mostra como sendo a melhor luz na relação.

\title{
CONSIDERATIONS ABOUT PHILOSOPHY, LAW AND ECOLOGY
}

\begin{abstract}
The relationship between man and nature have always been subject of inquiry in various prospects, from religion to science. How to relate these two poles, from the human behavioral relation to the prospect of law, in a convergent point is a challenge to human reflection. It is on this basis that this article was developed. Tools to face this challenge resulting from the analysis of three perspectives of thinking which deal differently with the relationship between man and nature, which are, anthropocentrism, ecology and solidary responsibility. As it seeks to demonstrate, it is in this latter that seems to us the best reason about the theme.
\end{abstract}

Keywords: Anthropocentrism. Ecology. Solidary Responsibility. Law. Nature.

\section{REFERÊNCIAS BIBLIOGRÁFICAS}

BACON, Francis, Sir. New Atlantis in Francis Bacon (1955). Chicago/ London/Toronto: William Benton, 1617.

ECKERSLEY, Robyn. Environmentalism and Political Theory: Toward an Ecocentric Approach. New York, State University of New York Press, 1992.

FERRY, Luc. A nova ordem ecológica. Rio de Janeiro: DIFEL, 2009.

JONAS, Hans. O princípio responsabilidade: ensaio de uma ética para uma civilização tecnológica. Rio de Janeiro: PUCRJ, 2006.

NAESS, A. The shallow and the deep, long range ecology movement. A summary., Inquiry, n. $16,1976$. 
OST, François. A natureza à margem da lei. Lisboa: Instituto Piaget, 1995. 2003.

La nature hors la loi, lécologie à I` épreuve du droit. Paris: La Découverte/ Poche,

RICOEUR, Paul. Postface au temps de la responsabilité, in Lectures I. Autour du politique. Paris: Le Seuil, 1991.

STONE, Christopher D. Should tress have Standing? Toward Legal rights for Natural Objects, in Southern California Law Review, Los Altos, Califórnia, 1972.

THOMAS, Keith. O homem e o mundo natural. Trad. João Roberto Martins Filho. São Paulo: Companhia de Bolso, 2010;

VERNANT, Jean Pierre. As origens do pensamento grego. Trad. Ísis Borges B. da Fonseca. Rio de Janeiro: Difel, 2002.

Trabalho enviado em 04 de abril de 2016.

Aceito em 10 de julho de 2016. 